\title{
Діагностика та лікування клінічно значущої портальної піпертензії. Огляд проблеми
}

\begin{abstract}
У роботі представлено вказівки щодо ведення пацієнтів, сучасних методів діагностики та лікування хворих із клінічно значущою портальною гіпертензією. Основний акцент в роботі зроблено на проблемі поза гострими геморагічними ускладненнями. Матеріал був розроблений на засіданні консенсусу Австрійського товариства з гастроентерології та гепатології (ÖGGH) та Австрійського товариства інтервенційної радіології (ÖGIR), що відбулося 18.02.2017 р., а також на основі клініко-практичного гайдлайну ведення пацієнтів із декомпенсованим цирозом Європейської асоціації з вивчення печінки (EASL, 2018 р.).
\end{abstract}

Ключові слова: діагностика; лікування; цироз печінки; портальна гіпертензія.

Близько 72 \% пацієнтів 3 цирозом печінки класу Child-Pugh B/C ускладнюються кровотечею з варикозу кардіо-езофагальних вен (BKEB) [1]. У решти пацієнтів із класом Child- Pugh А це ускладнення спостерігають у 42 \% [2]. За даними [3], у первинно виявленних пацієнтів із клаcoм Child-Pugh B/C без варикозу ймовірність його появи зростає на 7-8 \% щороку, а трансформація з малого варикозу у великий - до 22 \% щороку і до 51 \% впродовж 3-х років у пацієнтів із клаcom Child-Pugh B/C [4]. Смертність при кожному епізоді геморагій з ВКЕВ також висока - 15-25 \% впродовж 6 тижнів [5]. Без вторинної профілактики повторний епізод має місце в 60-70 \% випадків ще до року [6].

Мета роботи: спираючись на міжнародні рекомендації та враховуючи основні сучасні дослідження, метою даних рекомендацій є висвітлення останніх напрацювань щодо проблеми синдрому портальної гіпертензії; допомогти лікарям у діагностичній та терапевтичній роботі із пацієнтами з портальною гіпертензією.

На сьогодні основною причиною синдрому портальної гіпертензії є хронічні прогресуючі захворювання печінки (ПЗП) та бепосередньо цироз печінки, що входить в цю групу. Саме ці захворювання стають тригером для розвитку клінічно значущої портальної гіпертензії (КЗПГ). Критеріями для встановлення діагнозу синдрому портальної гіпертензії є визначення як збільшення гепатопортального градієнта тиску (ГПГТ) до значень $\geq 10$ мм рт. ст. (рівень доказовості (РД) A1) [7]. Необхідно зазначити, що субклінічна портальна гіпертензія буде варіювати при значеннях 6-9 мм рт. ст. (РД - А1), а нижче цих значень варіант норми. До того ж, КЗПГ може бути у пацієнтів без класичних клінічних проявів BKEB, асциту. Водночас наявність цих симптомів (при умові, що асцит гепатогенного характеру) i/чи значних порто-системних колатералей є індикатором КЗПГ (РД - А1).

Діагностика та скринінг портальної гіпертензії. Усі пацієнти з ПЗП підлягають скринінгу на предмет КЗПГ. Езофагогастроскопію (ЕГС) для виявлення BKEB (C1) в таких пацієнтів необхідно виконати хача б раз. Великим ВКЕВ варто вважати варикоз із діаметром вен більше 5 мм, додатково необхідно звертати увагу на червоні плями слизової в стратифікації ризику (А2). У разі ж відсутності ВКЕВ - наступну ЕГС неодхідно виконувати кожні 2 роки, за умови компенсованого, субкомпенсованого перебігу ПЗП та щороку при декомпенсованому. У випадку відсутніх данних про ПЗП, але при наявному ГПГТ до значень $\geq 10$ мм рт. ст. хворі підлягають щорічній ЕГС, оскільки КЗПГ прогнозує розвиток ВКЕВ (А1). При первинно виявлених великих ВKEВ не має показань щодо повторних ЕГС, за винятком випадків ендоскопічної корекції (В1) [7].

Первинна профілактика кровотечі з ВКЕВ. Усі хворі з великими вариксами ( $\geq 5$ мм) у кардіоезофагальному відділі мають бути ліковані 3 метою профілактики кровотечі з них або із застосуванням неселективних бета-блокатрів (НСББ) або iз ендоскопічним лігуванням варикозно-розширенних вен (ВРВ), (А1) [8]. Вибір методу здійснюється індивідуально. Щодо малих вариксів та червонних плям на слизовій ставоходу, шлунка, хворі на грунті декомпенсації ПСП (цирозу) мають приймати НСББ, це зменшує ризик кровотечі з них (A1), при цьому за відсутності ПСП приймання препаратів НСББ зменшує ризики з меншою достовірністю [12], (С1) [9]. Відомо, що НСББ не зменшують ризики розвитку КЗПГ у хворих із 
ПСП, а лише можуть знизити ризики розвитку асциту, (В2) [10].

Коли доступне визначення ГПГТ, слід віддавати перевагу НСББ, оскільки методика дає можливість якісно моніторити ефективність лікування (B1). Гемодинамічна реакція на НСББ визначається як зниження рівня ГПГТ $\leq 12$ мм рт. ст. або щонайменше $\geq 10 \%$ від базового рівня. Такий підхід пов'язаний не лише з нижчим ризиком перших варикозних кровотеч, але також із меншою частотою асциту та смерті [11] (А1). Однак недоступність визначення ГПГТ не повинна зупиняти у призначенні НСББ, що навіть у випадках низької чутливості до них статистично знижує частоту первинних кровотеч із BKEВ (B1) [12].

Ендоскопічне лігування вариксів (ЕВЛ). Лігування ВРВ слід рекомендувати у випадках протипоказань для НСББ або при їх непереносимості (B1) або ж при низькій відповіді на НСББ, яка за даними мета-аналізів не перевищує 46 \% [13]. Ендоскопічне лігування ВРВ слід проводити повторно з інтервалами 2-6 тижнів до повної ерадикації, з заключним контролем через 6 місяців та 1 раз на рік. Якщо ж виявляють рецидив - повертаються до тієї ж попередньої програми ендоскопічного лікування [9], (В1). Комбінація ендоскопічного лігування і НСББ достовірно не зменшує частоту кровотечі з ВКЕВ чи смерті, але підвищує ризики побічних ефектів і не рекомендована [10], (A1).

Неконтрольована кровотеча з ВKЕВ. Геморагічне ускладнення, що призводить до смерті або до наступних ускладнень впродовж 5-ти днів 3 моменту після першого епізоду кровотечі: свіжий гематомезис; гіповолемічний шок або гіпогемоглобінемія на $\geq 3$ г/л впродовж будь-якого 24-годинного періоду до тих пір, поки не проводиться переливання крові (B1).

Портальна гастро-інтестинопатія. Типово розвиток портальної гастро-інтестинопатії характерне після ендоскопічного лікування ВКЕВ шляхом перерозподілу венозної гіпертензії [14]. Клінічно така гастро-інтестинопатія проявляється як мозаїчний візерунок гіперемії слизової антрального відділу шлунка - так званий “кавунний шлунок”, наявністю субмукозного варикозу [15]. Подібні явища можуть виявлятися по усьому травному тракті [16]. Актуальність даної проблеми пов’ язана з розвитком “застійних” виразок шлунка, дуоденуму, кровотечі з них, а також із вариксів. Така ентеропатія є причиною хронічної залізодефіцитної анемії [17].

Трансюгулярне інтрапечінкове порто-системне иунтування (ТIПШ). ТІПШ у ранньому періоді (24-72 год) може запобігти розвитку не- контрольованої кровотечі, але за останніми дослідженнями є дані про зростання смертності при його застосуванні в цей період [18], (В1). Однак на сьогодні показаннями до ТІПШ є: пацієнти з ПЗП 3 класом Child-Pugh В 3 активною кровотечею при ендоскопії, незважаючи на вазоактивну терапію; пацієнти з ПЗП з класом Child-Pugh C з оцінкою 10-13; якщо ГПГТ становить $\geq 20$ мм рт. ст., (A1), а протипоказання - тяжка печінкова недостатність (клас Child-Pugh C (>13), MELD > 20), серцева недостатність (особливо правошлуночкова), легенева гіпертензія, анатомічні / технічні протипоказання, нерозрішена механічна жовтяниця або поширена печінкова малігнізація, (B1). Гостра пеінкова енцефалопатія на час гострої кровотечі з ВКЕВ не має протипоказання до ТІПШ, (C1), а вазоактивні препарати можна відміняти після успішного призначення ТІПШ, (C1). Балонна оклюзійна ретроградна трансвенозна облітерація (БРТО) може розглядатися у випадках триваючої кровотечі з ВРВ після ТІПШ або стійкі великі ВЕКВ після ТІПШ, (C1).

Вторинна профілактика кровотечі з ВЕКВ. Вторинну профілактику необхідно розпочати якнайшвидше у міру відміни вазоактивної терапії після кровотечі з ВЕКВ, (C1). Поєднання НСББ та ЕЛВ є терапією вибору для вторинної профілактики, (А2), [19]. Може бути застосована лише медикаментозна НСББ, якщо є підтвердженне зниження ГПГТ на 20 \%, або до абсолютних значень < 12 мм рт. ст., (А2). Невідповідачі НСББ у вторинній профілактиці вимагають коротких інтервалів ЕЛВ (кожні 2-4 тижні) до ерадикації ВЕКВ, (А2). У пацієнтів із протипоказаннями до НСББ, ЕЛВ самостійно може використовуватися для вторинної профілактики, (А2).

ЕЛВ для запобігання повторної кровотечі при вторинній профілактиці слід продовжувати з інтервалом 2-4 тижні до ліквідації варикозу, а потім слід повторити через 6 місяців і 12 місяців. Пацієнтів із запущеною стадією захворювання печінки слід готувати до трансплантації печінки. У цих пацієнтів ендоскопічну та/або медикаментозну терапію слід продовжувати до трансплантації печінки, (C2).

ТІПШ показана пацієнтам із невідповідною вторинною профілактикою і йому слід віддавати перевагу над хірургічним шунтуванням, (B1).

БРТО та хірургічна деваскуляризація кардіоезфагального відділу - це життєрятуючі операції в пацієнтів із невдачею вторинної профілактики із НСББ у поєднанні з ЕЛВ, якщо ні терапія ТІПШ, ні шунтуючі операції неможливо виконати, (C1). Застосування НСББ і ТІПШ необхідно враховувати із наявним рефрактерним асцитом, системни- 
ми гемодинамічними розладами, гострим ураженням нирок.

Вимірювання ГПГТ. Показанням для ГПГТ є оцінка прогнозу та моніторинг реакції на лікування КЗПГ [20], (А2). Для підбору і корегування терапевтичної дози НСББ [21], (В2). Так, якщо ГПГТ знижується до значення < 12 мм рт. ст. або зменшується на $\geq 20$ \% під час лікування НСББ, пацієнти захищені від кровотеча з ВЕКВ і виживаність збільшуються [22], (А1). Контроль портальної гемодинаміки при гострій кровотечі з ВЕКВ при проведенні лікування вазоактивними середниками достатньо в гострій обстановці [23], (А1). Загалом результати ГПГТ залишаються об'єктивним орієнтиром рішення щодо лікування [24], (А2). Технічно вимірювання ГПГТ слід проводити натще, при седації хворого за допомогою балонного катетера, що забезпечує достатнє заклинювання його позиції в печінковій вені на 2 см нижче нижньої порожнистої вени [25], (А1). В цій позиції реєструється середнє значення вільного печінкового венозного тиску. При роздуванні балона і його заклинення в позиції (перевірки позиції за допомогою контрастування) визначають тиск заклинення печінкової вени [26], (А1). Власне ГПГТ визнача-

\section{СПИСОК ЛІТЕРАТУРИ}

1. Clinical course of alcoholic liver cirrhosis: a Danish populationbased cohort study / P. Jepsen, P. Ott, P. K. Andersen [et al.] // Hepatology. - 2010. - Vol. 51. - P. 1675-1682.

2. Endoscopic screening for varices in cirrhotic patients: data from a national endoscopic database / M. Kovalak, J. Lake, N. Mattek [et al.] // Gastrointest. Endosc. - 2007. - Vol. 65. - P. 82-88.

3. Incidence and natural history of small esophageal varices in cirrhotic patients / M. Merli, G. Nicolini, S. Angeloni [et al.] // J. Hepatol. - 2003. - Vol. 38. - P. 266-272.

4. Beta-blockers to prevent gastroesophageal varices in patients with cirrhosis / R. J. Groszmann, G. Garcia-Tsao, J. Bosch [et al.] // N. Engl. J. Med. - 2005. - Vol. 353. - P. 2254-2261.

5. D’Amico G. Competing risks and prognostic stages of cirrhosis: a 25-year inception cohort study of 494 patients / G. D’Amico, L. Pasta, A. Morabito // A. Aliment. Pharmacol. Ther. - 2014. Vol. 39. - P. 1180-1193.

6. Bosch J. Prevention of variceal rebleeding / J. Bosch, J-C. Garcia-Pagan // Lancet. - 2003. - Vol. 361. - P. 952-954.

7. de Franchis R. Expanding consensus in portal hypertension: Report of the Baveno VI consensus workshop: Stratifying risk and individualizing care for portal hypertension / R. de Franchis, V. F. Baveno // J. Hepatol. - 2015. - Vol. 63. - P. 743-752.

8. Practice Guidelines Committee of the American Association for the Study of Liver Diseases. Practice Parameters Committee of the American College of Gastroenterology. Prevention and management of gastroesophageal varices and variceal hemorrhage in cirrhosis / G. Garcia-Tsao, A. J. Sanyal, N. D. Grace, W. Carey // Hepatology. - 2007. - Vol. 46. - P. 922-938.

9. Garcia-Pagan J-C. Review article: the modern management of portal hypertension-primary and secondary prophylaxis of varice- ють як різницю між заклиненим і вільним печінковим венозним тиском [26], (А1). Документальний облік реєстрування є обов’язковим [26], (А1).

Висновки. У роботі представлено сучасні підходи до діагностики, лікування геморагічно неускладненної КЗПГ, розроблені провідними асоціаціями лікарів-гепатологів, хірургів, радіологів-інтервенціоністі. Проблема лікування КЗПГ є надзвичайно актуальною і потребує мультидисциплінарного комплексного підходу спеціалістів (гастроентеролога-гепатолога, едоскопіста, абдомінального хірурга, інтервенціоніста, анестезіолога-реаніматолога (лікаря-токсиколога), лікаря-реабілітолога); складного комплексу діагностичного, лабораторного, відповідного технічно-інструментального оснащення для лікування такої складної категорії пацієнтів.

Перспективи подальших досліджень та їх застосування. У подальшому передбачається висвітлити проблеми ведення пацієнтів із клінічно значущою портальною гіпертензією, ускладненною гострою кровотечею з вариксів кардіоезофагального відділу. al bleeding in cirrhotic patients / J-C. Garcia-Pagan, A. De Gottardi, J. Bosch // Aliment. Pharmacol. Ther. - 2008. - Vol. 28. - P. 178-186. 10. Development of ascites in compensated cirrhosis with severe portal hypertension treated with beta-blockers / V. HernandezGea, C. Aracil, A. Colomo [et al.] // Am. J. Gastroenterol. - 2012. Vol. 107. - P. 418-427.

11. Carvedilol for primary prophylaxis of variceal bleeding in cirrhotic patients with haemodynamic non-response topropranolol / T. Reiberger, G. Ulbrich, A. Ferlitsch [et al.] // Gut. - 2013. Vol. - 62. - P. 1634-1641.

12. A randomized trial to assess whether portal pressure guided therapy to prevent variceal rebleeding improves survival in cirrhosis / C. Villanueva, I. Graupera, C. Aracil [et al.] // Hepatology. - 2017. - Vol. 65. - P. 1693-1707.

13. Value of the hepatic venous pressure gradient to monitor drug therapy for portal hypertension: a meta-analysis / A. Albillos, R. Banares, M. Gonzalez [et al.] // Am. J. Gastroenterol. - 2007. - Vol. 102. - P. 1116-1126.

14. Effects of endoscopic variceal ligation on portal hypertensive gastropathy and gastric mucosal blood flow / I. Yoshikawa, I. Murata, S. Nakano, M. Otsuki // Am. J. Gastroenterol. - 1998. - Vol. 93. - P. 71-74.

15. North Italian Endoscopic Club for the Study and Treatment of Esophageal Varices. Prediction of the first variceal hemorrhage in patients with cirrhosis of the liver and esophageal varices. A prospective multicenter study // N. Engl. J. Med. - 1988. Vol. 319. - P. 983-989.

16. Urrunaga N. H. Portal hypertensive gastropathy and colopathy / N. H. Urrunaga, D. C. Rockey // Clin. Liver. Dis. - 2014. Vol. 18. - P. 389-406. 
17. De Franchis RBaveno VI faculty. Expanding consensus in portal hypertension: report of the BAVENO VI Consensus Workshop: Stratifying risk and individualizing care for portal hypertension // J. Hepatol. - 2015. - Vol. 63. - P. 743-752.

18. Early-TIPSS placement prevents rebleeding in high-risk patients with variceal bleeding, without improving survival / M. Rudler, P. Cluzel, T-L. Corvec [et al.] // Aliment. Pharmacol. Ther. - 2014. - Vol. 40. - P. 1074-1080.

19. Drugs plus ligation to prevent rebleeding in cirrhosis: an updated systematic review / A. Puente, V. Hernandez-Gea, I. Graupera [et al.] // Liver. Int. - 2014. - Vol. 34. - P. 823-833.

20. Cirrhosis and portal hypertension: The importance of risk stratification, the role of hepatic venous pressure gradient measurement / V. la Mura, A. Nicolini, G. Tosetti, M. Primignani // World J. Hepatol. - 2015. - Vol. 7. - P. 688-695.

21. Mandorfer M. Beta-blocker sand cirrhosis 2016 / M. Mandorfer, T. Reiberger // Dig. Liver Dis. - 2017. - Vol. 49. - P. 3-10.

22. Relation between portal pressure response to pharmacotherapy and risk of recurrent variceal haemorrhagein patientswithcir- rhosis / F. Feu, J. C. Garcia-Pagan, J. Bosch [et al.] // Lancet. 1995. - Vol. 346. - P. 1056-1059.

23. Prognostic value of acute hemodynamic response to i. v. propranolol in patients with cirrhosis and portalhypertension / V. LaMura, J. G. Abraldes, S. Raffa [et al.] // J. Hepatol. - 2009. - Vol. 51. - P. 279-287.

24. Prevention of rebleeding from esophageal varices in patients with cirrhosis receiving small-diameter stents versus hemodynamically controlled medical therapy / T. Sauerbruch, M. Mengel, M. Dollinger [et al.] // Gastroenterology. - 2015. - Vol. 149 (e1). - P. 660-668.

25. Zipprich A. Comparison of balloon vs. straight catheter for the measurement of portal hypertension. / M. Winkler, T. Seufferlein, M. M. Dollinger // Aliment Pharmacol. Ther. - 2010. - Vol. 32. - P. 1351-1356.

26. Abraldes J-G. Measurement of portal pressure / J-G. Abraldes, P. Sarlieve, P. Tandon // Clin. Liver. Dis. - 2014. - Vol. 18. - P. 779-792.

\section{REFERENCES}

1. Jepsen, P., Ott, P., Andersen, P.K., Sorensen, H.T., \& Vilstrup, H. (2010). Clinical course of alcoholic liver cirrhosis: a Danish population-based cohort study. Hepatology, 51,1675-1682.

2. Kovalak, M., Lake, J., Mattek, N., Eisen, G., Lieberman, D. \& Zaman, A. (2007). Endoscopic screening for varices in cirrhotic patients: data from a national endoscopic database. Gastrointest. Endosc., 65, 82-88.

3. Merli, M., Nicolini, G., Angeloni, S., Rinaldi, V., De Santis, A., Merkel, C., et al. (2003). Incidence and natural history of small esophageal varices in cirrhotic patients. J. Hepatol., 38, 266-272. 4. Groszmann, R.J., Garcia-Tsao, G., Bosch, J., Grace, N.D., Burroughs, A.K., Planas, R., et al. (2005). Beta-blockers to prevent gastroesophageal varices in patients with cirrhosis. N. Engl. J. Med., 353, 2254-2261.

5. D’Amico, G., Pasta, L., \& Morabito, A., (2014). Competing risks and prognostic stages of cirrhosis: a 25-year inception cohort study of 494 patients. Aliment Pharmacol Ther, 39,1180-1193.

6. Bosch J., \& Garcia-Pagan J.C. (2003). Prevention of variceal rebleeding. Lancet, 361, 952-954.

7. de Franchis, R., \& Baveno, V.F. (2015) Expanding consensus in portal hypertension: Report of the Baveno VI consensus workshop: Stratifying risk and individualizing care for portal hypertension. J. Hepatol., 63,743-752.

8. Garcia-Tsao, G., Sanyal, A.J., Grace, N.D. , \& Carey, W. (2007) Practice Guidelines Committee of the American Association for the Study of Liver DiseasesPractice Parameters Committee of the American College of Gastroenterology. Prevention and management of gastroesophageal varices and variceal hemorrhage in cirrhosis. Hepatology, 46, 922-938.

9. Garcia-Pagan, J.-C., De Gottardi, A., \& Bosch, J. (2008). Review article: the modern management of portal hypertension-primary and secondary prophylaxis of variceal bleeding in cirrhotic patients. Aliment. Pharmacol. Ther., 28, 178-186.

10. Hernandez-Gea, V., Aracil, C., Colomo, A., Garupera, I., Poca, M., Torras, X., et al. (2012). Development of ascites in compensated cirrhosis with severeportal hypertension treatedwith betablockers. Am. J. Gastroenterol.,107, 418-427.

11. Reiberger, T., Ulbrich, G., Ferlitsch, A., Payer, B.A., Schwabl, P., Pinter, M., et al. (2013). Carvedilol for primary prophylaxis of variceal bleeding in cirrhotic patients with haemodynamic non-response topropranolol. Gut., 62, 1634-1641.

12. Villanueva, C., Graupera, I., Aracil, C., Alvarado, E., Minana, J., Puente, A., et al. (2017). A Randomized trial to assess whether portal pressure guided therapy to prevent variceal rebleeding improves survival in cirrhosis. Hepatology, 65 (5), 1693-1707.

13. Albillos, A., Banares, R., Gonzalez, M., Ripoll, C., Gonzalez, R., Catalina, M.V., et al. (2007). Value of the hepatic venous pressure gradient to monitor drug therapy for portal hypertension: a meta-analysis. Am, J, Gastroenterol., 102, 1116-1126.

14. Yoshikawa, I., Murata, I., Nakano, S., \& Otsuki, M. (1998) Effects of endoscopic variceal ligation on portal hypertensive gastropathy and gastric mucosal blood flow. Am. J. Gastroenterol., 93,71-74.

15. North Italian Endoscopic Club for the Study and Treatment of Esophageal Varices. Prediction of the first variceal hemorrhage in patients with cirrhosis of the liver and esophageal varices. A prospective multicenter study (1988). N. Engl. J. Med., 319, 983-989. 16. Urrunaga, N.H., \& Rockey, D.C. (2014) Portal hypertensive gastropathy and colopathy. Clin. Liver Dis., 18, 389-406.

17. De Franchis R., Baveno VIF. (2015). Expanding consensus in portal hypertension: Report of the Baveno VI consensus workshop: Stratifying risk and individualizing care for portal hypertension. J. Hepatol. 63,743-752.

18. Rudler, M., Cluzel, P., Corvec, T.L., Benosman, H., Rousseau, G., Poynard, T., et al. (2014). Early-TIPSS placement prevents rebleeding in high-risk patients with variceal bleeding, without improving survival. Aliment Pharmacol Ther., 40, 1074-1080. 19. Puente, A., Hernandez-Gea, V., Graupera, I., Roque, M., Colomo, A., Poca, M., et al. (2014). Drugs plus ligation to prevent rebleeding in cirrhosis: an updated systematic review. Liver Int., 34,823-833.

20. La Mura, V., Nicolini, A., Tosetti, G., \& Primignani, M. (2015). Cirrhosis and portal hypertension: The importance of risk stratification, the role of hepatic venous pressure gradientmeasurement. World J. Hepatol., 7, 688-695.

21. Mandorfer, M., \& Reiberger, T. (2016). Beta-blocker sand cirrhosis. Dig. LiverDis., 2017, 49, 3-10.

22. Feu, F., Garcia-Pagan, J.C., Bosch, J., Luca, A., Teres, J., Escorsell, A., et al. (1995). Relation between portal pressure response to pharmacotherapy and risk of recurrent variceal haemorrhagein patientswithcirrhosis. Lancet., 346, 1056-5109.

23. La Mura, V., Abraldes, J.G., Raffa, S., Retto, O., Berzigot- 
ti, A., GarciaPagan, J.C., et al. (2009). Prognostic value of acute hemodynamic response to $\mathrm{i}$. v. propranolol in patients with cirrhosis and portalhypertension. J. Hepatol., 51, 279-287.

24. Sauerbruch, T., Mengel, M., Dollinger, M., Zipprich, A., Rossle, M., Panther, E., et al. (2015). Prevention of Rebleeding from esophageal Varices in patients with cirrhosis receiving small-diameter stents versus hemodynamically controlled medi- cal therapy. Gastroenterology, 149, 660-668.

25. Zipprich, A., Winkler, M., Seufferlein, T., \& Dollinger, M.M. (2010). Comparison of balloon vs. straight catheter for the measurement of portal hypertension. Aliment Pharmacol. Ther., 32, 1351-1356.

26. Abraldes, J.G., Sarlieve, P., \& Tandon, P. (2014). Measurement of portal pressure. Clin. Liver Dis., 18, 779-792.

Електронна адреса для листування: t.romaniuk.cvs@gmail.com

T. V. ROMANIUK, I. K. VENHER, I. YA. DZUIBANOVSKYI

I. Horbachevsky Ternopil National Medical University

\title{
DIAGNOSIS AND TREATMENT OF CLINICALLY SIGNIFICANT PORTAL HYPERTENSION. OVERVIEW OF THE PROBLEM
}

This report provides guidelines for patient management, modern methods of diagnosis and treatment of patients with clinically significant portal hypertension. The main emphasis in the work is on the problem of non-acute hemorrhagic complications. The material was developed at a consensus meeting of the Austrian Society of Gastroenterology and Hepatology (ÖGGH) and the Austrian Society of Interventional Radiology (ÖGIR), held on February 18, 2017, as well as on the basis of clinical and practical guideline for patients with decompensated cirrhosis from the European Association of Studies of Liver (EASL, 2018).

Key words: diagnostics; treatment; liver cirrhosis; portal hypetension.

\section{Т. В. РОМАНЮК, И. К. ВЕНГЕР, И. Я. ДЗЮБАНОВСКИЙ}

Тернопольский национальный медицинский университет имени И. Я. Горбачевского МОз Украины

\section{ДИАГНОСТИКА И ЛЕЧЕНИЕ КЛИНИЧЕСКИ ЗНАЧИМОЙ ПОРТАЛЬНОЙ ГИПЕРТЕНЗИИ. ОБЗОР ПІРОБ.ЛЕМЫ}

\begin{abstract}
В данном сообщении представлены указания по ведению пациентов, современных методов диагностики и лечения больных с клинически значимой портальной гипертензией. Основной акцент в работе сделан на проблеме вне острых геморрагических осложнений. Материал был разработан на заседании консенсуса Австрийского общества по гастроэнтерологии и гепатологии (ÖGGH) и Австрийского общества интервенционной радиологии (ÖGIR), которое состоялось 18.02.2017 г., а также на основе клинико-практического гайдлайна ведения пациентов с декомпенсированным циррозом Европейской ассоциации по изучению печени (EASL, 2018).
\end{abstract}

Ключевые слова: диагностика; лечение; цирроз печени; портальная гипертензия. 